\title{
SELF-EFFICACY MATEMATIKA DAN SELF-EFFICACY MENGAJAR MATEMATIKA GURU MATEMATIKA
}

\author{
Pardimin \\ Universitas Sarjanawiyata Tamansiswa Yogyakarta Jl. Kusumanegara No.157, \\ Muja Muju, Umbulharjo, Kota Yogyakarta, 55165 \\ e-mail: pardimin@ustjogja.ac.id
}

\begin{abstract}
Self Efficacy in Mathematics and in Mathematics Teaching among Junior High-school Teachers. This study investigates teachers' self efficacy in mathematics and in mathematics teaching, involving 38 junior high school mathematics teachers in the city of Yogyakarta, Indonesia. The research instrument to measure self efficacy in mathematics consists of 18 questions with a reliability coefficient of .86, whereas the one to measure mathematics-teaching self efficacy consists of 18 statements with a reliability coefficient of .826 . Both instruments were adapted from the Mathematics Teaching and Mathematics Self-Efficacy Scale (MTMSE) developed by Kahle (2008). The results show that mathematics self efficacy and teaching mathematics self efficacy of the junior high school mathematics teachers in the city of Yogyakarta are high, with a correlation coefficient of .477. The mathematics selfefficacy instrument consists of three parts, namely arithmetics, algebra, and geometrics, and arithmetic self-efficacy is found to be positively correlated with teaching mathematics self-efficacy with a multiple correlation coefficient of .605 .
\end{abstract}

Keywords: mathematics self efficacy, mathematics teaching self efficacy, junior high-school mathematics teachers

\begin{abstract}
Abstrak: Self-Efficacy Matematika dan Self-Efficacy Mengajar Matematika Guru Matematika SMP Kota Yogyakarta. Self-efficacy matematika adalah konsep diri terkait kepercayaan individu pada kemampuannya untuk melakukan atau menyelesaikan suatu tugas atau masalah matematika. Selfefficacy mengajar matematika merupakan keyakinan seorang guru terhadap kemampuannya untuk mengatur dan melaksanakan tindakan pembelajaran matematika demi mencapai suatu tujuan serta yakin mampu untuk menghadapi segala tantangan dan mampu memprediksi seberapa besar usaha yang dibutuhkan untuk mencapai tujuan yang tepat dalam pembelajaran matematika. Penelitian tentang selfefficacy matematika self-efficacy mengajar matematika telah dilakukan terhadap 38 guru matematika SMP di kota Yogyakarta. Instrumen penelitian terdiri dari dua bagian. Pertama adalah instrumen selfefficacy matematika yang terdiri dari 18 petanyaan dengan koefisien reliabilitas sebesar 0,860 . Kedua adalah instrumen self-efficacy mengajar matematika yang terdiri dari 18 pernyataan dengan koefisien reliabilitas sebesar 0,826. Kedua intrumen tersebut diadaptasi dari Mathematics Teaching and Mathematics Self-Efficacy Scale (MTMSE) yang dikembangkan oleh Kahle (2008). Hasil penelitian menunjukkan bahwa self-efficacy matematika dan self-efficacy mengajar matematika guru SMP di kota Yogyakarta termasuk tinggi dengan koefisien korelasi antara keduanya sebesar 0,477. Instrumen self-efficacy matematika terdiri dari tiga bagian yaitu aritmatika, aljabar, dan geometrika. Hanya self-efficacy aritmatika yang berkorelasi positif dengan self-efficacy mengajar matematika dengan koefisien korelasi ganda sebesar 0,605 .
\end{abstract}

Kata kunci: self-efficacy matematika, self-efficacy mengajar, guru matematika

Self-efficacy adalah sebuah konsep yang dirumuskan oleh Bandura. Bandura (1997) menyatakan bahwa self-efficacy merupakan kepercayaan individu terhadap kemampuan dirinya untuk mencapai hasil yang sesuai dengan tujuan yang diharapkan. Self-efficacy merupakan upaya untuk memahami keberfungsian kehidupan manusia dalam pengendalian diri, pengaturan proses berpikir, motivasi, 
kondisi afektif, dan psikologis. Self-efficacy diyakini dapat membuat individu mampu menafsirkan dan menerjemahkan faktor-faktor internal dan eksternal ke dalam tindakan nyata.

Self-efficacy merupakan kemampuan umum yang terdiri atas aspek-aspek kognitif, sosial, emosional dan perilaku. Individu harus mampu mengolah aspek-aspek itu untuk mencapai tujuan tertentu. Self-efficacy merupakan sebuah instrumen multi guna karena tidak hanya berkaitan dengan kemampuan, namun juga keyakinan bahwa individu dapat melakukan berbagai hal dalam berbagai kondisi. Self-efficacy berlaku sebagai mesin pembangkit kemampuan manusia. Jika seseorang memiliki selfefficacy yang kuat, maka ia bermotivasi tinggi dan bahkan menunjukkan pandangan yang ekstrim dalam menghadapi suatu situasi (Bandura, 1997).

Self-efficacy tidak tumbuh dengan sendirinya, tetapi terbentuk dalam hubungan antara karakteristik pribadi, pola perilaku dan faktor lingkungan. Hubungan ini bersifat alami, personal dan sosial, dan mungkin terjadi proses yang panjang serta kompleks untuk menciptakan hubungan ini. Ada empat sumber informasi yang memberikan kontribusi penting terhadap pembentukan self-efficacy, yaitu pengalaman tentang keberhasilan pribadi (enactives mastery experiences), pengalaman keberhasilan orang lain yang dijadikan model (vicarious experiences), pujian dan penghargaan sosial (verbal persuasion and other related social recognitions), dan keadaan psikologis serta afektif individu (physiological and affective states).

Bandura dan Adams (1977) mengemukakan bahwa ada empat faktor yang mempengaruhi selfefficacy. Pertama, pengalaman keberhasilan yang berupa keberhasilan dan kegagalan. Pengalaman keberhasilan akan menaikkan self-efficacy individu, sedangkan pengalaman kegagalan akan menurunkannya. Kedua, pengalaman orang lain (vicarious experience). Pengamatan terhadap keberhasilan orang lain dengan kemampuan yang sebanding dalam mengerjakan suatu tugas akan meningkatkan Self-efficacy individu dalam mengerjakan tugas yang sama. Begitu pula sebaliknya, pengamatan terhadap kegagalan orang lain akan menurunkan penilaian individu mengenai kemampuannya dan individu akan mengurangi usaha yang dilakukan. Ketiga, persuasi verbal (verbal persuation). Pada persuasi verbal, individu diarahkan dengan saran, nasihat, dan bimbingan sehingga dapat meningkatkan keyakinannya tentang kemampuan-kemampuan yang dimiliki yang dapat membantu mencapai tujuan yang diinginkan. Individu yang diyakinkan secara verbal cenderung akan berusaha lebih keras untuk mencapai suatu keberhasilan. Keempat, kondisi fisiologis (physiological state). Individu akan mendasarkan informasi mengenai kondisi fisiologis mereka untuk menilai kemampuannya. Ketegangan fisik dalam situasi yang menekan dipandang individu sebagai suatu tanda ketidakmampuan karena hal itu dapat melemahkan performansi kerja individu tersebut.

Individe dengan self-efficacy tinggi cenderung menunjukkan usaha yang lebih keras dibandingkan individu dengan tingkat self-efficacy yang rendah. Self-efficacy mempengaruhi pola pikir dan reaksi emosional individu, baik dalam menghadapi situasi saat ini maupun dalam mengantisipasi situasi yang akan datang. Fitriana, et al. (2015) menemukan bahwa orang dengan self-efficacy yang tinggi akan berusaha lebih keras untuk mengatasi tantangan yang ada. Self-efficacy juga memainkan satu peran penting dalam memotivasi pekerja untuk menyelesaikan pekerjaan yang menantang dalam kaitannya dengan pencapaian tujuan tertentu. Individu dengan self-efficacy yang rendah selalu menganggap dirinya kurang mampu menangani situasi yang dihadapinya. Dalam mengantisipasi keadaan, mereka juga cenderung mempersepsikan masalah-masalah yang akan timbul jauh lebih berat daripada yang sesungguhnya. Individu dengan self-efficacy yang tinggi akan mempersepsikan dirinya sebagai orang yang berkompetensi tinggi. Ia akan merasa tertantang jika dihadapkan pada tugas-tugas dengan derajat kesulitan dan resiko yang tinggi. Sebaliknya, orang dengan self-efficacy yang rendah akan menganggap dirinya tidak kompeten dan menganggap kegagalan akibat dari ketidakmampuannya (Bandura, 1997).

Self-efficacy dimiliki oleh setiap individu, termasuk guru. Hoy (dalam Protherhoe, 2008) menyatakan bahwa self-efficacy guru adalah keyakinan guru akan kemampuannya dalam meningkatkan pembelajaran siswanya. Self-efficacy guru merupakan keyakinan guru akan kemampuannya dalam mengatur dan melaksanakan program yang diperlukan agar berhasil menyelesaikan tugas pembelajaran. Bray-Clark dan Bates (2003) menyatakan bahwa self-efficacy guru merupakan pendorong utama keefektifan dan kemampuan inovasi seorang guru. Guru yang efektif percaya bahwa mereka dapat membuat perbedaan dalam kehidupan siswa, dan mereka mengajar dengan cara-cara yang menunjukkan keyakinan ini. Guru yang efektif memahami materi pelajaran dan cara menetapkan tujuan dan mencapai sasaran untuk diri mereka sendiri dan siswanya. Guru yang efektif adalah perencana yang 
baik, selalu siap, menampilkan pengetahuan pedagogis yang baik, menampilkan kelas yang baik, keterampilan manajemen, dan menggabungkan kegiatan interaktif dalam ruang kelas. Guru yang efektif dapat mengontrol bagaimana mereka berpikir, bertindak, dan menanggapi dan yakin pada kemampuan untuk mengajar siswa secara efektif. Senemoglu, et al., (2009) melaporkan bahwa guru yang mempunyai self-efficacy yang tinggi akan menunjukkan kepercayaan yang tinggi akan pengetahuan dan keterampilan mereka, sehingga akan menghasilkan pembelajaran yang efektif. Berdasarkan hasil-hasil penelitian tentang self-efficacy guru, Dibapile (2012) menyimpulkan bahwa Self-efficacy membantu guru dalam merencanakan strategi pembelajaran yang efektif, meningkatkan kinerja, dan meningkatkan keefektifan serta produktifitas guru. Schunk (1981) serta Mojavezi dan Tamiz (2012) melaporkan bahwa Self-efficacy berkaitan dengan motivasi dan performance. Nurlu (2015) melaporkan bahwa guru dengan Self-efficacy yang lebih tinggi memiliki beberapa karakteristik yang berbeda dengan guru yang memiliki self-efficacy lebih rendah, seperti menunjukkan perhatian yang lebih tinggi berkaitan dengan upaya dan ketekunan siswa, lebih terbuka untuk ide-ide baru dan metode baru, lebih meyakini keberhasilan siswa, lebih bertanggung jawab terhadap keberhasilan siswa, lebih bertanggung jawab atas keberhasilan siswa, dan menjalin hubungan lebih akrab dengan siswa dibandingkan dengan orang tuanya.

Gibson dan Dembo (dalam Wahyuni \& Mustikawan) mengidentifikasi ada dua komponen dari self-efficacy, yaitu personal teacher efficacy (PTE) dan general teacher efficacy (GTE). PTE mengarah pada keyakinan guru bahwa dia mampu menjadi seorang guru, sedangkan GTE mengacu pada peran lingkungan dalam mengontrol keberhasilan seorang guru.

Self-efficacy berhubungan dengan keyakinan guru akan kemampuannya melakukan tugas-tugasnya dalam mengatur kegiatan pembelajaran. Umpan balik positif terhadap kemampuan seseorang akan memberikan dampak meningkatnya selfefficacy. Self-efficacy dapat mempengaruhi tingkat keberhasilan seseorang untuk menyelesaikan tugas yang dihadapinya (Alivernini \& Lucidi, 2011). Self-efficacy dapat meningkatkan usaha dan ketekunan seseorang terhadap tugas-tugas yang menantang sehingga tugas tersebut dapat diselesaikan. Tingginya self-efficacy seseorang dipengaruhi oleh pengalaman yang dimilikinya dalam menghadapi tugas tertentu (Yilmaz \& Çavaş, 2008). Ünsal, et al. (2016) melaporkan bahwa tingginya self-efficacy guru dipengaruhi oleh lamanya mengajar dan level variabel yang ada disekolah.

Matematika merupakan ilmu universal yang mendasari perkembangan teknologi modern, mempunyai peran penting dalam berbagai disiplin dan memajukan daya pikir manusia. Perkembangan pesat di bidang teknologi informasi dan komunikasi dewasa ini dilandasi oleh perkembangan matematika di bidang teori bilangan, aljabar, analisis, teori peluang dan diskrit. Untuk menguasai dan menciptakan teknologi di masa depan diperlukan penguasaan matematika yang kuat sejak dini (Setiana, 2015).

Matematika merupakan salah satu mata pelajaran yang cenderung menjadi momok bagi siswa. Ketakutan siswa terhadap pelajaran matematika akan berpengaruh pada hasil belajar siswa. Siswa cenderung menganggap matematika sebagai mata pelajaran yang sulit sehingga prestasi belajarnya cenderung rendah. Data dari National Center for Education Statistic (NCES) tahun 2003 menunjukkan bahwa prestasi pelajar matematika siswa Indonesia termasuk rendah, yaitu berada di peringkat 39 dari 41 negara, di bawah Thailand dan Uruguay.

Terkait dengan kondisi yang ada, peranan guru sangat berarti dalam mengubah persepsi siswa terhadap mata pelajaran matematika. Guru dapat mengubah persepsi siswa terhadap matematika dengan beberapa cara. Diantaranya adalah mengubah metode pembelajaran matematika dari berbagai macam metode pembelajaran matematika. Kemampuan guru dalam memilih metode pembelajaran ini dipengaruhi oleh kemampuan yang dimiliki oleh guru untuk menjawab tantangan pembelajaran matematika. Kemampuan inilah yang harus dimiliki oleh setiap guru matematika. Guru matematika dengan self-efficacy yang tinggi cenderung mampu menjawab tantangan tersebut.

Tujuan dari pembelajaran matematika adalah untuk mengembangkan kemampuan penalaran dan kemampuan logika siswa, serta menjadi salah satu metode untuk mengembangkan pola penalaran siswa secara sistematis (Sembiring, et al., 2008). Pembelajaran matematika merupakan suatu proses yang dipengaruhi oleh berbagai faktor, yaitu tujuan pembelajaran, guru, peserta didik, kegiatan pengajaran, dan sistem evaluasi (Djamarah, 2010). Faktorfaktor tersebut saling bersinergi dan merupakan aspek yang saling berkaitan dalam ketercapaian keberhasilan pembelajaran matematika. Ditinjau dari segi guru, dalam pembelajaran matematika diperlukan guru yang memiliki kemampuan matematika serta keterampilan mengajar yang mumpuni agar tujuan pembelajaran matematika dapat tercapai 
dengan maksimal. Kemampuan matematika serta keterampilan mengajar yang dimiliki guru berkaitan erat dengan self-efficacy guru.

Self-efficacy matematika adalah konsep diri terkait kepercayaan individu pada kemampuannya untuk melakukan atau menyelesaikan suatu tugas atau masalah matematika (Yates, 2014). Self-efficacy mengajar matematika merupakan keyakinan seorang guru terhadap kemampuannya untuk mengatur dan melaksanakan tindakan pembelajaran matematika demi mencapai suatu tujuan serta yakin mampu untuk menghadapi segala tantangan dan mampu memprediksi seberapa besar usaha yang dibutuhkan untuk mencapai tujuan yang tepat dalam pembelajaran matematika. Self-efficacy mengajar matematika berhubungan dengan tingkat kepercayaan kemampuan guru untuk mengajar sesuai standar tertentu (Kahle, 2008). Zuya, et al. (2016) mengemukakan bahwa self-efficacy guru matematika (mathematical selfefficacy) memiliki hubungan yang signifikan dengan self-efficacy mengajar guru matematika (mathematics teaching self efficacy).

Peker (2016) mengemukakan bahwa dimensi kepercayaan diri pada kesadaran mengajar matematika memiliki pengaruh pada kepercayaan diri mengajar seorang guru. Khan (2011) melaporkan adanya keterkaitan atau hubungan yang baik antara self-efficacy guru matematika dengan capaian prestasi siswa. Tasdemir (2016) menambahkan bahwa perbedaan gender dalam efikasi diri tidak berpengaruh pada pelajaran matematika. Hasil penelitian Briley (2012) menunjukkan bahwa guru dengan kepercayaan yang tinggi pada kemampuan mereka dalam mengajar matematika memiliki rasa percaya diri yang tinggi dalam menyelesaikan permasalahan dalam matematika.

Beberapa penelitian membuktikan bahwa selfefficacy guru memiliki korelasi positif dengan hasil belajar membaca dan matematika (Alivernini \& Lucidi, 2011). Para peneliti lain juga membuktikan pengaruh self-efficacy guru terhadap elemen-elemen pengajaran. Self-efficacy guru merupakan satu kontributor signifikan terhadap perbedaan individu dalam efektivitas pengajaran. Penelitian Laili dan Rahmawati (2015) menyimpulkan bahwa terdapat pengaruh kompetensi profesional guru matematika terhadap self efficacy. Pengaruh yang positif dan signifikan dari self-efficacy terhadap kinerja mengajar guru juga telah dibuktikan oleh penelitian Jumari, et al. (2013). Swars (2005) menemukan bahwa kekuatan teacher efficacy berhubungan dengan pengalaman matematika sebelumnya.

Permasalahannya adalah tidak semua guru matematika memiliki efikasi diri yang tinggi. Hera- waty (2016) melaporkan bahwa sebagian besar guru di Kabupaten Bengkulu Selatan dan Kepahang, Provinsi Bengkulu memiliki kinerja dan self-efficacy yang rendah dalam pembelajaran matematika. Masih banyak ditemukan guru mengajar tidak merujuk pada perencanaan pembelajaran yang ada, guru hanya memanfaatkan acuan yang ada dalam buku cetak sebagai pegangannya. Sudjiono (2014) melaporkan bahwa salah satu faktor internal non-kognitif yang berpengaruh besar terhadap prestasi belajar matematika adalah self-efficacy. Baginya peningkatan self-efficacy matematika dalam proses pembelajaran matematika di SMP sangat penting. Disamping sebagai elemen kunci sukses untuk belajar matematika, efikasi diri merupakan variabel terpenting dalam self-regulated learning dan mempengaruhi fungsi kognisi, afeksi, dan konasi siswa.

Sejauh ini dapat dianggap belum ada penelitian yang mengkaji secara khusus tentang tingkat self-efficacy matematika dan tingkat self-efficacy mengajar matematika guru matematika SMP di Indonesia serta hubungan antara keduanya. Penelitian ini bertujuan untuk mengungangkapkan tingkat self-efficacy matematika dan tingkat self-efficacy mengajar matematika guru matematika SMP serta hubungan antara keduanya.

\section{METODE}

Populasi penelitian ini adalah seluruh guru matematika SMP di Kota Yogyakarta. Sampel penelitian diambil menggunakan teknik purposive sampling. Sampel yang memenuhi kriteria adalah guru matematika SMP yang memiliki pengalaman mengajar matematika lebih dari 1 tahun. Sampel penelitian yang diperoleh adalah 38 guru matematika SMP.

Penelitian ini mengadopsi instrumen penelitian yang dikembangkan oleh Kahle (dalam Yates, 2014) yaitu Mathematics Teaching and Mathematics Self-Efficacy Scale (MTMSE). Bagian satu dan tiga berkaitan dengan self efficacy matematika. Bagian dua dan empat berkaitan dengan self-efficacy mengajar guru matematika. Bagian lima berkaitan dengan orientasi konseptual dan prosedural pengajaran. Bagian enam berkaitan dengan pertanyaan demografis.

Instrumen dari penelitian ini dikembangkan dari dua bagian instrumen MTMSE yaitu bagian pertama tentang self-efficacy matematika dan bagian dua tentang self-efficacy mengajar guru matematika. Instrumen self-efficacy matematika terdiri dari 18 pertanyaan yang merupakan terjemahan dari tes aslinya. Pada setiap pertanyaan guru diminta untuk 
menilai kepercayaan diri mereka dalam memecahkan masalah-masalah matematika tanpa menggunakan kalkulator. Setiap jawaban dinyatakan dengan skala Likert dari satu sampai lima. Skala satu untuk jawaban sangat tidak yakin dan skala lima untuk jawaban sangat yakin. Hasil uji coba instrumen ini terhadap 15 orang guru matematika di SMP Taman Dewasa Yogyakarta menghasilkan koefisien korelasi item-total dalam rentangan 0,40-0,83 dan koefisien alpha cronbach sebesar 0,860. Karakteristik subjek uji coba adalah sama dengan yang digunakan oleh Kahle (2008), yaitu guru matematika SMP. Uji coba yang dilakukan oleh Kahle menghasilkan koefisien alpha cronbach sebesar 0,900. Terjemahan dari instrumen tersebut diberikan di Tabel 2.

Instrumen self-efficacy mengajar guru matematika dikembangkan dari instrumen MTMSE bagian dua. Instrumen aslinya terdiri dari 13 pernyataan. Dalam penelitian ini dari 13 pernyataan tersebut dikembangkan menjadi 18 pernyataan untuk menjaring informasi yang lebih lengkap tentang self-efficacy mengajar guru matematika. Guru diminta untuk menjawab pernyataan tentang pengajaran matematika yang mereka lakukan. Setiap jawaban dinyatakan dengan skala Likert dari satu sampai lima. Skala satu untuk jawaban sangat tidak setuju dan skala lima untuk jawaban sangat setuju. Hasil uji coba instrumen ini terhadap 15 orang guru matematika di SMP Taman Dewasa Yogyakarta menghasilkan koefisien korelasi item-total dalam rentangan $0,40-0,83$ dan koefisien alpha cronbach sebesar 0,826. Karakteristik subjek uji coba adalah sama dengan yang digunakan oleh Kahle (2008), yaitu guru matematika SMP. Pernyataan tentang self-afficacy mengajar matematika guru matematika diberikan pada Tabel 3.

Data penelitian merupakan skor total dari harga skala Likert yang diberikan oleh guru. Selfefficacy matematika dan self-efficacy mengajar matematika dianggap tinggi bila harganya antara 4-5 dalam skala Likert, dianggap rendah bila harganya antara 3-4, dan dianggap sangat rendah bila harganya kurang dari 3. Data yang diperoleh dianalisis secara deskriptif kuantitatif dan analisis korelasi antara self-efficacy matematika dan self-efficacy mengajar matematika.

\section{HASIL DAN PEMBAHASAN}

Sampel atau responden penelitian ini adalah 38 orang guru matematika SMP di Kota Yogyakarta. Karakteristik responden diberikan pada Tabel 1.

Data pada Tabel 1 menunjukkan bahwa sebagian besar responden $(36,8 \%)$ usianya diatas 45 ta- hun. Hal ini menunjukkan bahwa sebagian besar guru matematika SMP di Kota Yogyakarta merupakan guru yang sudah senior atau berpengalaman dalam mengajar matematika. Pengalaman ini sangat mempengaruhi self-efficacy dan self-efficacy mengajar matematika guru SMP tersebut. Hal ini paralel dengan pernyataan William (2015) yaitu pengalaman dan keyakinan diri memiliki pengaruh yang kuat terhadap tingkat self-efficacy seseorang. Data pada Tabel 1 juga menunjukkan bahwa 60,5\% guru matematika SMP di Kota Yogyakarta telah mengajar lebih dari 10 tahun.

\section{Tabel 1. Karakteristik Responden}

\begin{tabular}{cccc}
\hline Demografi & Deskripsi & Frekuensi & $\%$ \\
\hline Jenis Kelamin & Pria & 9 & 23,7 \\
& Wanita & 29 & 76,3 \\
Asal Sekolah & Negeri & 14 & 36,8 \\
& Swasta & 24 & 63,2 \\
Usia & $21-25$ tahun & 6 & 15,8 \\
& $26-35$ tahun & 7 & 18,4 \\
& $36-45$ tahun & 11 & 28,9 \\
Lama Menjadi Guru & $>$ 45 tahun & 14 & 36,8 \\
& $1-5$ tahun & 9 & 23,7 \\
& $6-10$ tahun & 6 & 15,8 \\
Jenjang Pendidikan & $>10$ tahun & 23 & 60,5 \\
& Sarjana S1 & 33 & 86,8 \\
& Sarjana S2 & 5 & 13,2 \\
\hline
\end{tabular}

Self-sfficacy matematika dan self-efficacy mengajar matematika guru matematika SMP kota Yogyakarta diberikan pada Tabel 2 dan 3.

Self-efficacy guru matematika adalah konsep diri terkait kepercayaan guru pada kemampuannya untuk melakukan atau menyelesaikan suatu tugas atau masalah matematika (Yates, 2014). Data pada Tabel 2 menunjukkan bahwa self-efficacy guru matematika SMP di Kota Yogyakarta termasuk dalam kategori tinggi. Hasil penelitian ini paralel dengan hasil penelitian yang dilakukan oleh Unlu \& Ertekin (2013) terhadap calon guru matematika sekolah dasar yang menyimpulkan skala self-efficacy mengajar matematika dan skala self-efficacy matematika termasuk kategori tinggi.

Data penelitian menunjukkan bahwa tingkat keyakinan guru matematika SMP di kota Yogyakarta dalam mengerjakan persoalan matematika termasuk tinggi. Self-efficacy guru yang tinggi ini memberikan modal yang besar untuk dapatnya guru matematika SMP di kota Yogyakarta mengajar matematika secara efektif. Berdasarkan pendapat yang dikemukakan oleh Bray-Clark dan Bates (2003) maka self-efficacy guru matematika SMP di kota Yog yakarta yang tinggi ini dapat menjadi pendorong utama keefektifan dan kemampuan inovasi mereka. 
Tabel 2. Skala Rata-Rata Self Efficacy Matematika Guru Matematika SMP Kota Yogyakarta

\begin{tabular}{rrr}
\hline & Persoalan & Skala
\end{tabular}

1. Suatu segitiga mempunyai sisi pendek $6 \mathrm{~cm}$, dan sisi yang panjang 2 kali dari sisi yang pendek, sisi yang ketiga 4,4 $3,4 \mathrm{~cm}$ lebih pendek dari sisi yang panjang. Berapa jumlah panjang semua sisi dari segitiga.

2. Berapa kali dari 614.360 menghasilkan 30.668 .000

3. Terdapat tiga angka bilangan. Angka yang kedua 2 kali lebih besar dari angka pertama. Angka pertama adalah sepertiga dari angka ketiga. Jumlah ketiga angka tersebut adalah 48. Bilangan keberapa dengan angka tertinggi.

4. Ada 5 titik yang terletak pada satu garis lurus. T disebelah G. K disebelah H. C disebelah T. H disebelah G. Tentukan urutan kelima titik tersebut.

5. Jika $y=9+x / 5$, tentukan $x$ jika $y=10$

6. Pemain baseball mendapat 2 skor dalam 3 kali pukulan. Ini dapat ditulis sebagai $2 / 3$. Berapa angka dalam bentuk desimal yang paling sesuai dengan skor tersebut.

7. Jika $\mathrm{P}=\mathrm{M}+\mathrm{N}$, yang mana persamaan berikut yang benar?

a. $\mathrm{N}=\mathrm{P}-\mathrm{M}$

b. $\mathrm{P}-\mathrm{N}=\mathrm{M}$

c. $\mathrm{N}+\mathrm{M}=\mathrm{P}$

d. benar semua a,b,c

8. Hitunglah sudut yang terbentuk pada saat jam 8 tepat.

9. Amir membeli paket buku yang terdiri dari buku yang berharga Rp 9.000 dan Rp 13.000. Amir membayar sebesar Rp 265.000. Jika ada 25 buku dalam paket tersebut, berapa jumlah buku yang berharga Rp 13.000

10. Dalam suatu peta, $7 / 8 \mathrm{~cm}$ mewakili $200 \mathrm{~km}$. Berapa jarak antara dua kota yang di dalam peta sepanjang $3 \frac{1}{2} \mathrm{~cm}$.

11. Fredy membayar suatu perlengkapan rumah pada suatu toko sebesar Rp 136.400. Jika dia membayar dengan uang Rp 200.000, berapa kembalian uang yang dia terima

12. Orang biasanya menggunakan rumus berikut untuk menentukan rata-rata berat anak laki-laki umur $1-7$ tahun: $\mathrm{B}=17+5 \mathrm{U}$ dimana $\mathrm{B}$ adalah berat dalam $\mathrm{kg}$ dan $\mathrm{U}$ adalah umur dalam tahun. Menurut rumus tersebut, setiap kenaikan umur, apakah berat nya akan bertambah atau berkurang, dan berapa perubahannya?

13. Maria mengikuti lima kali test untuk pelajaran matematika. Setiap tes bernilai 25 point. Rata-rata nilai tes Maria untuk empat kali tes adalah 15 . Berapa kemungkinan rata-rata tertinggi yang dia dapatkan untuk kelima tes tersebut

$14.35 / 8-1 / 2=\ldots \ldots \ldots . . .$.

15. Dalam suatu auditorium, kursi biasanya disusun dalam sejumlah $x$ baris dan $y$ kursi dalam satu baris. Karena pembicaranya terkenal, ditambahkan sejumlah baris dan sejumlah kursi dalam satu baris. Jadi ada $x+1$ baris dan $y+1$ kursi dalam setiap baris. Tuliskan kedalam persamaan matematika untuk menunjukkan jumlah orang yang akan duduk dalam pengaturan baru tersebut

16. Suatu roda mempunyai keliling $80 \mathrm{~cm}$. Jarak antara dua titik $S$ dan T adalah $10 \mathrm{~cm}$. Tentukan berapa derajat sudut yang terbentuk seperti dalam berikut.

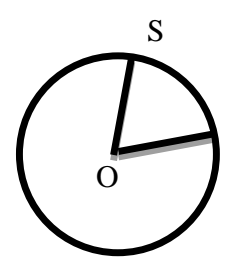

17. Tuliskan persamaan dari pernyataan "enam kurang dari dua kali $45 / 6$ "

18. Dua segitiga dibawah ini adalah serupa. Jadi sisi yang bersesuaian adalah proporsional, dan $\mathrm{AC} / \mathrm{BC}=\mathrm{XZ} / \mathrm{YZ}$ jika $\mathrm{AC}=1,7 \mathrm{~cm} \mathrm{BC}=2 \mathrm{~cm}$ dan $\mathrm{XZ}=5,1 \mathrm{~cm}$ tentukan berapa panjang $\mathrm{YZ}$
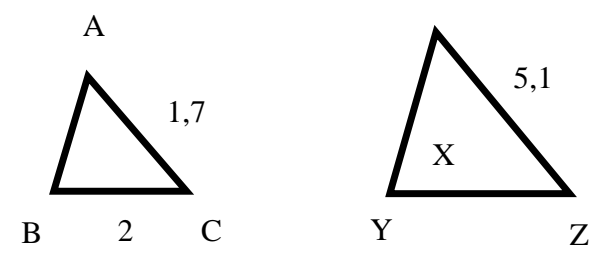
Tabel 3. Skala Rata-Rata Self Efficacy Mengajar Matematika Guru Matematika SMP Kota Yogyakarta

\begin{tabular}{|c|c|c|}
\hline & Pernyataan & Skala \\
\hline 1. & Saya berpikir bahwa saya cukup memadai untuk mengajar semua konsep-konsep matematika. & 3,8 \\
\hline 2. & $\begin{array}{l}\text { Saya percaya bahwa saya bisa menyelesaikan semua masalah matematika jika saya mencoba dengan cukup } \\
\text { keras }\end{array}$ & 4,2 \\
\hline 3. & Saya tidak tahu apa yang harus dilakukan ketika saya menghadapi masalah matematika & 4,3 \\
\hline 4. & Saya tidak memiliki banyak pengalaman mengajar matematika seperti rekan-rekan saya di sekolah. & 3,9 \\
\hline 5. & Saya tidak tahu bagaimana mengembangkan sikap positif terhadap matematika & 4,2 \\
\hline 6. & Saya akan terus mencari cara yang lebih baik untuk mengajar matematika & 4,6 \\
\hline 7. & Saya berusaha keras untuk dapat mengajar matematika sebagai mata pelajaran yang paling disukai & 4,5 \\
\hline 8. & Saya tahu bagaimana mengajarkan konsep-konsep matematika secara efektif & 3,7 \\
\hline 9. & Saya tidak akan efektif dalam memantau aktivitas matematika di kelas & 4,1 \\
\hline & Saya umumnya akan mengajar matematika secara efektif & 4,0 \\
\hline 11. & $\begin{array}{l}\text { Saya memahami konsep-konsep matematika cukup baik agar menjadi efektif dalam mengajar matematika di } \\
\text { SMP }\end{array}$ & 3,8 \\
\hline 12. & $\begin{array}{l}\text { Saya merasa sulit untuk menggunakan peraga untuk menjelaskan kepada siswa mengapa bagaimana konsep } \\
\text { matematika }\end{array}$ & 2,4 \\
\hline & Saya biasanya dapat menjawab pertanyaan yang diajukan oleh siswa & 4,2 \\
\hline & Saya tidak tahu apakah saya memiliki keterampilan yang diperlukan untuk mengajar matematika & 3,9 \\
\hline & $\begin{array}{l}\text { Jika diberi pilihan, saya tidak akan mengundang kepala sekolah untuk mengevaluasi pengajaran matematika } \\
\text { saya }\end{array}$ & 4,1 \\
\hline & $\begin{array}{l}\text { Ketika siswa mengalami kesulitan memahami konsep matematika, saya biasanya akan bingung bagaimana } \\
\text { untuk membantu siswa agar memahami dengan lebih baik }\end{array}$ & 4,1 \\
\hline & Ketika mengajar matematika, saya biasanya menerima pertanyaan-pertanyaan dari siswa & 4,0 \\
\hline & Saya tidak tahu bagaimana mengubah siswa suka dengan matematika & 3,9 \\
\hline & Rata-rata & 4,0 \\
\hline
\end{tabular}

Self-efficacy guru dalam mengajar matematika berhubungan dengan tingkat kepercayaan kemampuan guru untuk mengajar matematika sesuai standar tertentu (Kahle, 2008). Data pada Tabel 3 menunjukkan bahwa self-efficacy mengajar guru matematika SMP di Kota Yogyakarta termasuk dalam kategori tinggi. Hal ini menunjukkan bahwa tingkat keyakinan guru matematika SMP di kota Yogyakarta dalam mengajarkan matematika matematika termasuk tinggi. Self-efficacy mengajar guru matematika yang tinggi ini mengindikasikan keyakinan dan kecakapan guru untuk mempengaruhi siswa dalam memilih aktivitas dan mempengaruhi tingkat keterlibatan individu dalam kegiatan pembelajaran matematika. Guru dalam penelitian ini sangat setuju bahwa mereka adalah guru yang efektif yang terus berusaha melakukan inovasi dalam mengajar matematika.

Self-efficacy matematika dan self-efficacy mengajar matematika guru SMP di kota Yogyakarta memiliki hubungan yang positif dan signifikan.
Koefien korelasi antara keduanya, dihitung dengan persamaan product moment, adalah 0,477 , dengan taraf signifikansi 0,002 . Hubungan ini termasuk cukup kuat. Hal ini menunjukkan bahwa kontribusi self-efficacy matematika dalam menjelaskan sel-f efficacy mengajar matematika adalah sebesar 22,8\%.

Adanya hubungan positif dan signifikan antara self-efficacy matematika dan Self-efficacy mengajar matematika kiga ditemukan oleh Unlu \& Ertekin (2013). Bates, Latham, dan Kim (2011) juga menunjukkan bahwa self-efficacy calon guru matematika berkorelasi positif dengan kinerja personal dalam mengajar matematika. Hanya calon guru yang sangat percaya diri dengan kemampuan mereka untuk mengajar percaya bahwa mereka dapat memberikan dampak positif terhadap siswa. Adanya hubungan positif dan signifikan antara self-efficacy matematika dan self-efficacy mengajar matematika juga dilaporkan oleh Bates, et al. (2011).

Instrumen self-efficacy matematika terdiri dari tiga bagian yaitu aritmatika, aljabar, dan geome- 
trika. Ketiga kemampuan tersebut juga diuji kontribusinya terhadap self-efficacy mengajar matematika seperti ditunjukkan pada Tabel 4.

\section{Tabel 4. Analisis Regresi Self-Efficacy Guru Matematika dengan Self Efficacy Mengajar Guru Matematika}

\begin{tabular}{|c|c|c|c|c|c|}
\hline & B & Beta & $\mathbf{T}$ & Sig. & Kesimpulan \\
\hline (Constant) & $1,62^{\prime}$ & & 3,04 & 0,00 & \\
\hline SE_aritmatika & 0,53 & 0,62 & 3,28 & $0,00^{\prime}$ & Signifikaı \\
\hline SE_aljabar & $-0,11 !$ & $-0,22 i$ & $-0,96 t$ & 0,34 & Tidak signifikaı \\
\hline SE_geometri & 0,12 & $0,19 !$ & 0,92 . & 0,36 & Tidak signifikaı \\
\hline
\end{tabular}

Hasil analisis regresi menunjukkan bahwa dari tiga self-efficacy matematika yang terdiri dari aritmatika, aljabar, dan geometrika hanya aritmatika yang berpengaruh signifikan terhadap selfefficacy mengajar matematika. Dengan demikian faktor yang dominan mempengaruhi self-efficacy mengajar matematika adalah self-efficacy matema-

\section{DAFTAR RUJUKAN}

Alivernini, F \& Lucidi, F. 2011. Relationship between Social Context, Self-Efficacy, Motivation, Academic Achievement, and Intention to Drop Out of High School: a longitudinal study. The Journal of Education Research, 104, 241-252.

Bandura. A. 1997. Self-Efficacy (The Exercise of Control). New York: W. H. Freeman and Company.

Bandura, A \& Adams, N.E. 1977. Analysis of Self-efficacy Theory of Behavioral Change. New York: Stanford University.

Bates, A.B., Latham, N., \& Kim, J. 2011. Linking Preservice Teachers' Mathematics Self-Efficacy and Mathematics Teaching Efficacy to Their Mathematical Performance. School and Mathematics, 111(7), 325-333.

Bray-Clark, N. \& Bates, R. 2003. Self Efficacy Beliefs and Teacher Effectivenness: Implications for Profesional Developments. The Proffesional Educator, XXIV(1), 13-22.

Briley, J.S. 2012. The Relationships Among Mathematics Teaching Efficacy, Mathematics Self-Efficacy, and Mathematical Beliefs for Elementary PreService Teachers. Issues in the Undergraduate Mathematics Preparation and School Teachers: The Journal, Vol. 5, 1-13.

Dibapile, W.T.S. 2012. A Review of Literature on Teacher Efficacy and Classroom Management. Journal of College Teaching and Learning, Second Quarter, 9(2), 79-91.

Djamarah, S.B. 2010. Strategi Belajar Mengajar. Jakarta: Rieneka Cipta. tika khususnya aritmatika. Hasil analisis regresi juga menunjukkan nilai $\mathrm{R}^{2}$ sebesar 0,366 . Hal ini berarti kontribusi self-efficacy aritmatika dalam menjelaskan self-efficacy mengajar matematika adalah sebesar $36,6 \%$.

\section{SIMPULAN}

Self-efficacy matematika dan self-efficacy mengajar matematika guru matematika SMP di Kota Yogyakarta termasuk dalam kategori tinggi. Korelasi antara keduanya termasuk cukup dengan koefisien korelasi sebesar 0,477. Berarti, self-efficacy matematika dalam menjelaskan self-efficacy mengajar matematika adalah sebesar $22,75 \%$. Instrumen selfefficacy matematika terdiri dari tiga bagian yaitu aritmatika, aljabar, dan geometrika. Korelasi ganda antara self-efficacy aritmatika dengan self-efficacy mengajar matematika termasuk kuat dengan koefisien korelasi sebesar 0,605. Hal ini berarti kontribusi self-efficacy aritmatika dalam menjelaskan selfefficacy mengajar matematika adalah sebesar 36,6\%.

Fitriana, S., Ihsan, H., \& Annas, S. 2015. Pengaruh Efikasi Diri, Aktivitas, Kemandirian Belajar dan Kemampuan Berpikir Logis Terhadap Hasil Belajar Matematika pada Siswa Kelas VIII SMP. Journal of Educational Science and Technology, 1(2), 86-101.

Fritz, William, F. (2015). The Efficacy Beliefs of Elementary Teachers Including A Specific Emphasis on Mathematics. A Disesertation Major in Educational Leadership in the Department of Graduate Education, March. Northwest Nazarene University.

Herawaty, D. 2016. Pengaruh Kecerdasan Emosional, Partisipasi Guru dalam Forum Ilmiah, Keyakinan Diri (Self Efficacy), dan Motivasi Kerja terhadap Kinerja Guru Matematika. Jurnal Review Pembelajaran Matematika, 1(1), 71-85.

Jumari, Yudana, M., \& Sunu, I.A. 2013. Pengaruh Budaya Organisasi, Efikasi Diri dan Kepuasan Kerja Terhadap Kinerja Mengajar Guru SMK Negeri Kecamatan Denpasar Selatan. e-Journal Program Pascasarjana Universitas Pendidikan Ganesha. Program Studi Administrasi Pendidikan, 4(1), 1-13.

Kahle, D.K.B. 2008. How elementary school teachers' mathematical self efficacy and mathematics teaching self-efficacy relate to conceptually and procedurally oriented teaching practices. Doctoral dissertation Ohio State University. Diakses dari http://etd.ohiolink.edu/view.cgi?acc_num= osu1211122861. 
Khan, A. 2011. Teacher Efficacy - a Tool to Enhance Academic Achievement of Secondary Schools. Language in India, 11(6): 235-247.

Laili, P.A. \& Rahmanawati, F.Y. 2015. Pengaruh Persepsi Kompetensi Profesional Guru Matematika Terhadap Self Efficacy Matematika Pada Siswa SMAN 1 Jember. INSIGHT, 11(2), 159-166.

Mojavezi, A. \& Tamiz, M.P. 2012. The Impact of Teacher Self-Efficacy on the Students' Motivation and Achievement. Theory and Preactice in Language Studies, 2(3), 483-491.

Nurlu, Ö. 2015. Investigation of Teacher Mathematics Teaching Self Efficacy. International Electronic Journal of Elementary Education, 8(1), 21-40.

Peker, M. 2016. Mathematics Teaching Anxiety and Self-Efficacy Beliefs Toward Mathematics Teaching: A Path Analysis. Educational Research and Review, 11(3), 97-104.

Protherhoe, N. 2008. Teacher Efficacy: What is it and does it matter? Principal, May/June, 42-45.

Rizkiana, A. 2017. Pengaruh self efficacy terhadap Hasil Belajar Mahasiswa Berprestasi (mawapres) STKIP PGRI Bangkalan. Equilibrium, 5(2), 117122.

Schunk, D.H. 1995. Self-Efficacy, Motivation and Performance. Journal of Applied Sport Psychology, 7(2), 112-137.

Sembiring, R.K., Hadi, S., \& Dolk, M. 2008. Reforming Mathematics Learning in Indonesian Classrooms Through RME. ZDM-The International Journal on Mathematics Education, 40(6), 927-939.

Senemoglu, N., Demirel, M., Yagci, E., \& Ustudag, T. 2009. Elementary School Teachers' Self-Efficacy Beliefs: A Turkish Case. Humanity \& Social Sciences Journal, 4(2), 164-171.

Setiana. 2015. Peer Tutoring dan Program Catch Kaitannya dengan Self Efficacy. Seminar Nasional Matematika dan Pendidikan Matematika Universitas Negeri Yogyakarta 2015.

Sudjiono. 2014. Pengaruh Mind Mapping terhadap Peningkatan Efikasi Diri Matematika dan Prestasi
Belajar Matematika Siswa SMP. Disertasi Doktor tidak diterbitkan, Universitas Gajah Mada.

Swars, S. 2005. Examining Perceptions of Mathematic Teaching Effectivennes among Elementary Preservice Teachers with Differing Levels of Mathematics Teacher Efficacy. Journal of Instructional Psychology, 32(2), 202-248.

Tasdemir, C. 2016. An Examination of Vocational School Students Self Efficacy Beliefs in Mathematics and of Their Achievement Levels. Educational research and reviews, 11(8), 804-811.

Unlu, M. \& Ertekin, E. 2013. The Relationship between Mathematics Teaching Self-Efficacy and Mathematics Self-Efficacy. Social and behavioral sciences, 106(10), 3041-3045.]

Ünsal, S., Korlmaz, F., \& Percin, S. 2016. Analysis of Mathematics Teachers' Self-Efficacy Levels Concerning the Teaching Process, Journal of Education and Practice, 7(24), 99-107.

Wahyuni, E.N \& Mustikawan, A. 2018. Self Efficacy Guru Pendidikan Agama Islam dalam Mengembangkan Pendidikan Karakter Siswa (Penelitian Survey terhadap Guru-guru Pendidikan Agama Islam Madrasah di Jawa Timur). Conference Proceedings. Annual International Conference on Islamic Studies (AICIS XII), 191-206.

Yates, T.H. 2014. Teachers' Self-Efficacy in Mathematics and Teaching Mathematics, Instructional Practices, and the Mississippi Curriculum Test, Second Edition for Mathematics in Grades 3-5. Dissertations. Paper 241.

Yilmaz, H. \& Çavaş, P.H. 2008. The Effect of the Teaching Practice on Pre-service Elementary Teachers' Science Teaching Efficacy and Classroom Management Beliefs. Eurasia Journal of Mathematics Science and Technology Education, 4(1): 4554.

Zuya, H.E., Kwalat, S.K., \& Attah, B.G. 2016. Preservice Teachers'Mathematics Self-Efficacy and Mathematics Teaching Self-Efficacy. Journal of Education and Practie, 7(14): 93-98. 